\title{
UMA LEITURA COMPARADA DA GUERRA SANTA NO APOCALIPSE DE JOÃO E NO ROLO DA GUERRA DE QUMRAN
}

Valtair A. Miranda

\section{RESUMO}

A relação entre o fim do mundo e algum tipo de guerra de proporções cósmicas era um tema proeminente na expectativa judaica, com a ressalva de que nessas tradições o povo de Deus não teria qualquer função no conflito. Deus lutaria sozinho com seu exército celestial. Há apenas dois casos em que o exército humano do Senhor luta ao lado dos anjos: Apocalipse de João (década de 90 do séc. I da Era Comum) e Rolo da Guerra de Qumran (II séc. antes da Era Comum). Neste artigo, num exercício de leitura comparada, a proposta é estudar a ideologia da guerra santa subjacente a estas narrativas, bem como as possíveis implicações deste tipo de perspectiva no cotidiano de sua audiência.

\section{PALAVRAS-CHAVE}

Apocalipse de João, Rolo da Guerra, Guerra santa, história comparada.

\section{ABSTRACT}

The relationship between the end of the World and war in cosmic dimensions was a prominent aspect of Jewish expectations. In these religious traditions people of God have no participation in the battle,

\footnotetext{
${ }^{1}$ Doutor em Ciências da Religião. Pesquisador associado do Programa de Estudos Medievais da Universidade Federal do Rio de Janeiro.
} 
and only God and His Celestial Army will fight. However, there are two texts that present both God' human army and angels: Revelation of John (end of first century CE) and Qumran War Scroll (second century BC). This essay presents the ideology of Holy War behind these narratives by using the resources of Compared Literature. It also indicates possible implications these ideologies have in daily life of their audience.

\section{KEY-WORDS}

Revelation of John, War Scroll, Holy War, Compared History.

A comparação pode tanto olhar para o que é individual e peculiar em cada fenômeno quanto o que é similar e comum a ambos. Nas palavras de Thelml e Bustamante: "O processo comparativo é justamente o que permite estabelecer o estranhamento, a diversificação, a pluralização e a singularidade daquilo que parecia empiricamente diferente ou semelhante, posto pelo habitus e reproduzido pelo senso comum"2. Isso vale para comparações de gênero, grupos sociais, partidos, nações, territórios, religião, costumes, imaginário, etc.

Comparar, assim, está na própria base da atividade histórica. Paul Veyne, na sua aula inaugural no Colégio de França, em 1975, resumiu duas posturas diante dos fatos históricos. Na primeira, o historiador designa e descreve. Na segunda, ele tenta explicitar a originalidade do fato, encontrar palavras ou conceitos para traduzi-lo ou destacá-lo em relação aos invariantes ${ }^{3}$.

É neste sentido que Veyne argumenta que qualquer história se torna história comparada, já que o historiador, na sua prática, separa sabendo por que o faz. Desta forma, a história tem como tarefa conceitualizar para demonstrar ou apreender a originalidade das coisas ${ }^{4}$.

\footnotetext{
${ }^{2}$ THELML, Neyde; BUSTAMANTE; Regina M. da Cunha. História comparada: olhares plurais, p. 15.

${ }^{3}$ VEYNE, Paul. O inventário das diferenças, p. 30. Por invariante, Veyne entende a teoria histórica ou as ferramentas da explicação.

${ }^{4}$ VEYNE, Paul. O inventário das diferenças, p. 31.
} 
A tentativa deste artigo, no contexto da análise comparativa, é relacionar dois documentos da antiguidade. Ambos são de origem judaica, e estão separados no tempo por mais ou menos dois séculos (dependendo da data postulada para o Rolo da Guerra). Tentaremos aplicar a estes documentos a tipologia da guerra santa (nos termos de Veyne, o invariante) levantada por Gerhard Von Rad para o antigo Israel ${ }^{5}$.

\section{A guerra santa no antigo Israel}

Von Rad propôs uma tipologia para a guerra santa no antigo Israel ${ }^{6}$ com os seguintes elementos:

- A convocação, como ilustrada pelo texto de Juízes 6.34-35;

- Depois de reunido o exército, eles passam a ser chamados de "povo de Deus", como Juízes 5.11;

- Todos os homens são consagrados, geralmente envolvendo algum tipo de renúncia sexual (1Sm 21.5);

- Os guerreiros oferecem sacrifícios, que têm como função remover qualquer barreira que possa impedir Yahweh de agir (1Sm 13.9-10);

- Busca-se um sinal, através de algum oráculo, da vontade divina sobre o confronto (Jz 20.18);

- Uma fórmula padrão é usada: "Yahweh tem dado o adversário em nossas mãos" (Js 2.24);

- A fórmula "Yahweh tem ido a nossa frente" também é freqüente (Js 3.11). Deus se move à frente para preparar o caminho, tornando-se, assim, co-guerreiro. Ele está envolvido no combate (Dt 20.4), porque, no final é ele mesmo quem vence a guerra (2Sm 5.24);

- O conflito é declarado "guerra de Yahweh" (Nm 21.14);

- Os inimigos são declarados "inimigos de Yahweh" (Jz 5.31);

\footnotetext{
${ }^{5}$ VON RAD, Gerhard. Holy War in Ancient Israel. Grand Rapids: Eerdmans Publishing Co., 1991.

${ }^{6}$ Para uma história do tema até von Rad, conferir OLLENBURGER, Ben C. Introduction: Gerhard von Rad's Theory of Holy War. In: VON RAD, Gerhard. Holy War in Ancient Israel. Grand Rapids: Eerdmans Publishing Co., 1991, pp. 1-33.
} 
- Quando o exército de Israel se aproxima, um senso de medo domina o adversário, levando-o a perder a coragem (Ex 15.14-16);

- A medida que o combate começa e as forças se enfrentam, ouvese um grito de guerra. Freqüentemente, trombetas também eram tocadas (Jz 7.20);

- Um terror divino cai sobre os inimigos. Eles já haviam perdido a coragem, agora se vêm envolvidos em um absoluto pânico (Ex 23.27);

- A prática do extermínio, onde o inimigo é entendido como santo ou dedicado ao Senhor, é o ponto alto da guerra santa (1Sm 15.3; Js 6.18-19);

- Ao ouvir a frase "para suas tendas, ó Israel", a guerra está concluída (2Sm 20.1).

Evidentemente, nem todos os elementos da tipologia aparecem em todas as narrativas de guerra santa. Mas o principal elemento, que especificamente marcava o evento como uma guerra consagrada, estava na forma como o conflito aparece mergulhado em elementos litúrgicos, dirigido e sancionado por ritos e mandamentos tradicionais e religiosos?

Como fenômeno histórico ${ }^{8}$, a guerra santa esteve circunscrita ao período da conquista e da posse de Canaã, intimamente ligada ao contexto tribal e ao processo de criação de uma identidade étnica que daria origem à nação de Israel ${ }^{9}$.

\footnotetext{
${ }^{7}$ VON RAD, Gerhard. Holy War in Ancient Israel, p. 51.

${ }^{8}$ Trataremos, acompanhando Von RAd, o fenômeno da guerra santa e a tradição da guerra santa como elementos distintos. Como fenômeno, ela estaria restrita ao período tribal. A partir daí, apenas como tradição. Cf. VON RAD, Gerhard. Holy War in Ancient Israel, p. 60. Walzer, entretanto, sugeriu uma hipótese diferente. Segundo ele, a guerra santa totalizante seria uma construção retrospectiva dos tempos da monarquia como resposta para o perigo da miscigenação. Efetivamente, ela nunca teria sido implementada em Israel, e só aparece idealizada nos textos como forma de convencer os possíveis leitores do perigo das relações com outros povos. Cf. WALZER, Michael. The Idea of Holy War in Ancient Israel, p. 223.

9 Em termos históricos, a guerra santa não foi um fenômeno exclusivo do antigo Israel. Havia paralelos entre os povos contemporâneos. Tanto Israel quanto os povos vizinhos procuravam revestir suas ações militares de perspectivas religiosas.
} 
Apesar de abandonada como fenômeno, entretanto, ela sobreviveu como tradição, renascendo em textos religiosos que iriam ser incorporados posteriormente à Escritura judaica. Em função de novas realidades, como uma crítica mesmo à instituição militar e às práticas militares da monarquia, o elemento da atuação de Deus é exacerbado. Ele age e vence sozinho. As milícias de Israel não atuam mais no confronto.

\section{O Rolo da Guerra de Qumran}

Em 1947, dois pastores descobriram por acaso a primeira gruta de Qumran, à beira do Mar Morto. Foram encontrados fragmentos e rolos escritos em hebraico. A partir de então, outras grutas foram sendo encontradas, contendo muito material em grande parte identificado como oriundo do cânon judaico. Até 1956 seriam descobertas um total de 11 grutas, com inúmeros fragmentos de papiro e jarros com escrita em grego $^{10}$.

O mundo ainda estava tentando esquecer a Segunda Grande Guerra quando esses documentos começaram a ser divulgados. Quando poucos ainda tinham idéia do alcance do achado arqueológico, um documento identificado como 1QM, ou 1Q33, foi colocado ao alcance dos estudiosos. Apelidado pelo surpreendente nome de "A Guerra dos filhos da luz contra os filhos das trevas", foi publicado ainda em 1947 por Eleazar Lipa Sukenik da Universidade Hebraica de Jerusalém. Sukenik morreu antes de publicar sua versão anotada, mas essa tarefa foi concluída por seu filho Ygael Yadin, em Hebraico (1955) e, posteriormente, em inglês $(1962)^{11}$.

Cf. MILLER, Patrick D. God the Warrior: a Problem in Biblical Interpretation and Apologetics. In: Interpretation, 19, 1965, p. 42.

${ }^{10}$ MARTÍNEZ, Florentino García. Textos de Qumran. Petrópolis: Vozes, 1995, p. 20; também WINSON, Edmund. Os manuscritos do Mar Morto. São Paulo: Companhia das Letras, 1994. 246 p; TROMPF, Garru W. Introduction I: The Long History of Dead Sea Scrolls Scholarship. In: The Journal of Religious History, 26/2, 2002, pp. 123-144.

${ }^{11}$ A edição oficial de 1QM está em SUKENIK, Eleazar L. The Dead Sea Scrolls 
As principais questões da discussão inicial eram sobre quando foi escrito e como foi estruturado. Apesar do seu primeiro comentarista (Yadin) ter defendido uma unidade interna, a maioria dos estudiosos entendeu que o documento tem natureza composta, formado de textos de épocas diferentes.

As colunas 2-9 do manuscrito parecem ser do tempo da guerra dos macabeus, como um manual para o esperado conflito entre Israel e as nações. A coluna 15-19 apesar de retroceder também ao tempo da guerra macabaica, contem elementos redacionais do período romano. Seu conteúdo consiste de uma moldura para a guerra, liturgia e narrativas de batalha. Sua estrutura apresenta uma ética dualística não encontrada no nacionalismo da coluna 2-9. Os guerreiros de Israel são os filhos da luz e as nações são os filhos das trevas, o exército de Belial.

A coluna 10-12 é uma coleção de hinos e orações, algumas até de origem macabaica, como a "oração para o tempo de batalha". A coluna 13 contem hinos e partes de um ritual de benção e cura, além de uma cerimônia de aliança. Relaciona-se fortemente com as colunas 15-19. Outro fragmento, preservado na coluna 14, consiste de hinos de agradecimento pela vitória, também refletindo a situação e a teologia do período dos macabeus.

of the Hebrew University. Jerusalém: Magnes Press, 1955, pp. 1-19; 16-34; 47. Fragmentos relacionados foram apresentados em:

- 1Q33: BARTHÉLEMY, Dominique; MILIK, Josef T (eds). Qumran Cave I (Discoveries in the Judaean Desert I). Oxford: Clarendon, 1955, pp. 135-136.

- 4Q491-497: BAILLET, Maurice (ed.). Qumran Grotte 4.III (Discoveries in the Judaean Desert 7). Oxford: Clarendon, 1982, pp. 12-72.

- 11Q14: GARCIA MARTINEZ, Florentino (ed.) Qumran Cave 11.II (Discoveries in the Judaean Desert 23). Oxford: Clarendon, 1998, pp. 243-251.

- 4Q471b-471c: CHAZON, Esther (ed.) Qumran Cave 4 XX. Poetical and Liturgical texts, Part 2 (Discoveries in the Judaean Desert 29). Oxford: Clarendon, 1999, pp. 421-435.

- 4Q471b, 4Q285, 4Q471-471a: PFANN, Stephen (ed.) Qumran Cave 4. XXVI (Discoveries in the Judaean Desert 36). Oxford: Clarendon, 2000, pp. 199-205; 228-246; 439-449.

Neste artigo, as citações são feitas basicamente das edições: GARCIA MARTINEZ, Florentino. The Dead Sea Scrolls Study Edition. 2 vols. Leiden: Brill, 2000; GARCÍA MARTÍNEZ, Florentino. Textos de Qumran. Petrópolis: Vozes, 1995. 
O livro é aberto com a coluna 1, composta para iniciar o manuscrito, contendo um sumário introdutório da guerra, combinando a linguagem e as idéias das outras seções de 1QM. A redação final, neste caso, parece ser de cerca de 50 antes da Era Comum.

Percebe-se que o principal elemento do Rolo da Guerra é a forma como ele sintetiza num só relato guerra e cerimônia religiosa, fazendo com que não encontre paralelo entre os apocalipses, nas outras regras de Qumran ou nos manuais militares da época. No Rolo da Guerra, as tropas se movem ao som de trombetas, como se a batalha fosse um evento litúrgico.

O Rolo ainda descreve o acampamento de guerra como um local puro ritualmente. Deste lugar, os combatentes se envolvem nas várias fases do conflito escatológico. Desta base militar, vários grupos de pessoas são excluídos: menores de idade (7.1-3); crianças e mulheres (7.34); coxos, cegos, paralíticos, pessoas com uma impureza indelével na carne e pessoas impuras ritualmente (7.4-5); quem não fosse perfeito em espírito e corpo (7.6); homens que não se purificassem de sua fonte; nudez indecente perto do acampamento (7.7). Esta lista tem grande semelhança com a lista de inaptidões dos sacerdotes em Levítico 21.1624. Essa comparação ilumina como o Rolo interpreta a própria guerra. A luta dos Filhos da Luz contra os Filhos das Trevas é um evento religioso, porque os combatentes estão envolvidos com ações comparáveis ao ministério sacerdotal.

A narrativa do cronista, ao apresentar a tradição da guerra santa na sua forma mais estilizada, se aproxima consideravelmente do que encontramos no Rolo da Guerra. Tomemos, então, a tipologia da guerra santa do antigo Israel como postulada por Von Rad e a cruzemos com 1QM:

- A convocação dos guerreiros para a batalha (1QM 2.7; 15);

- O povo, no acampamento, é chamado de "povo de Yahweh" (1QM 3.13);

- Os homens são consagrados (1QM 7.3-7), e as armas também (1QM 6.2-3);

- Mencionam-se as ofertas sacrificiais (1QM 2.5-6);

- O desejo de um sinal ou oráculo para determinar a vontade de Deus está ausente, talvez porque a comunidade entendia que os 
guerreiros não precisavam dessa consulta em função da guerra ser o conflito do final dos tempos (1QM 1.13); 11.13);

- A fórmula "Yahweh tem dado o inimigo em nossas mãos" (1QM

- A fórmula "Yahweh move-se a nossa frente" (1QM 10.4);

- A fórmula "a guerra santa é a guerra de Yahweh" (1QM 10.4);

- O inimigo é também inimigo de Yahweh (1QM 12.10; 19.3);

- Os inimigos perdem a coragem (1QM 1.6) antes da batalha;

- O grito de guerra (1QM 8.7-11). Em 16.6-7, entretanto, há um período de silêncio antes do conflito, o que talvez possa ser entendido como expressão cúltica, porque logo depois os sacerdotes tocam os chifres. De qualquer forma, existe um grito de guerra presente (1QM 1.17);

- $\mathrm{O}$ divino terror vem sobre os inimigos durante a batalha (1QM 4.7);

- O extermínio está subjacente. Segundo 1QM 14.5, o lote de Belial está sob maldição divina. A destruição completa de Belial e seu lote é o efeito final visualizado em 1QM 17.4-5;

- A fórmula "para suas tendas, o Israel", ou seja, a dispersão, é a segunda característica da guerra santa que não está incluída no Rolo da Guerra, talvez porque o Rolo descreva uma guerra que terminaria no fim dos tempos. Não haveria "tendas" para retornar.

A tradição da guerra santa, pelo que percebemos, manifestou-se no Rolo da Guerra no contexto histórico-social da revolta dos macabeus. Essa situação foi o terreno fértil para que este documento voltasse a inserir na tradição da guerra santa o sinergismo da participação humana no confronto, como já realizado pela literatura de 1Macabeus (1Mc 3.44-4.25) e 2 Macabeus (2Mc 3.24-27). Nesta comparação, entretanto, apenas o Rolo da Guerra de Qumran deu seqüência a predominância dos sacerdotes e levitas na guerra, mantendo na tradição os elementos litúrgicos.

O principal resultado do uso deste Rolo na comunidade de Qumran parece ser a acentuação e definição, em termos cada vez mais rígidos, da identidade ascética ${ }^{12}$ e sectária do grupo a ele subjacente.

${ }^{12}$ Thiering apontou os principais elementos ascéticos evidenciados nos textos da comunidade de Qumran: celibato, ausência de propriedades pessoais, jejum, vigílias, 
Altas demandas de pureza estão diretamente relacionadas com a já mencionada lista de inaptidões. A exclusão de todas essas pessoas do acampamento da guerra escatológica estava baseada nas demandas de pureza ritual, estágio de pureza esse que só era originalmente associado com o Templo de Jerusalém, mas que agora era estendido para o acampamento. Mesmo sendo uma descrição escatológica, o relato tinha implicação direta para o cotidiano da comunidade de Qumran. Para ela, eles estavam acampados contra o adversário ${ }^{13}$. A comunidade era um acampamento de guerra, o que implicava que todos os seus membros precisavam estar ritualmente puros e prontos para participar do conflito escatológico, independente do momento em que ele brotasse. As mulheres, crianças e qualquer outra pessoa com potencial de contaminação religiosa deveriam ser excluídos do grupo, já no presente, não necessariamente nos dias de combate futuro.

A tendência, então, era segregar os agentes de possíveis contaminações, levando a práticas ascéticas, entre elas o celibato e a misoginia. Mas não apenas as mulheres seriam excluídas do grupo. Também as crianças e pessoas com deficiência física.

No momento de descrever os adversários, esse potencial ascético se desdobra em potencial sectário. Apesar do texto também falar dos adversários de Deus e seu povo em termos tradicionais, como as nações, ou os Kittim, ele insere o elemento dualista (luz e trevas), fazendo com que eles sejam caracterizados, então, como Filhos das Trevas, incluindo neste grupo os "desertores da aliança", ou seja, pessoas que antes eram irmãs, mas que agora não eram mais ${ }^{14}$. A guerra, que antes era definida em termos étnicos, agora é postulada em termos morais, enrijecendo, assim, as fronteiras sectárias do grupo. Agora há um cri-

comportamento sóbrio, obediência à estrutura, legalismo. Cf. THIERING, Barbara. The Biblical Source of Qumran Asceticism. In: Journal of Biblical Literature, 93/3, 1974, pp. 429-432.

${ }^{13}$ Para Parker, o acampamento militar era o mais antigo "santo dos santos". Cf. PARKER, James O. The Genres of the Dead Sea War Scroll, pp. 87, 94.

${ }^{14}$ Expressão que Pagels usa para descrever o surgimento do sectarismo no contexto judaico. Cf. PAGELS, Elaine. As origens de satanás, p. 75. 
tério para a auto-identidade da comunidade diferente de distinções étnicas ${ }^{15}$.

Nota-se, também, que a principal preocupação do Rolo da Guerra, em suas várias fases e versões, não era com as táticas militares ${ }^{16}$, mas com os aspectos rituais e religiosos do conflito que os habilitaria a ter a ajuda dos anjos de Deus. Eram estes aspectos que deveriam ser cumpridos rigorosamente para participar da vitória já determinada "segundo os mistérios de Deus" (1QM 16.11), e não necessariamente as estratégias militares dos combatentes. Parece ser esse o motivo que faz com que os sacerdotes e levitas tenham uma maior função no Rolo do que os comandantes militares, ou mesmo o Príncipe da Congregação (com exceção da sua participação messiânica em 4Q285 e 11Q14). Ao transformar a guerra num ritual, os guerreiros teriam o apoio dos anjos no meio deles (1QM 7.6). O resultado final parece ser um rolo de guerra escatológica que desejava orientar sacerdotes e levitas na participação do conflito final. Seriam eles as peças fundamentais na condução da guerra, de tal forma que seus atos liberariam a ajuda celestial na luta contra os adversários do povo de Deus ${ }^{17}$.

Assim, apesar de descrever a guerra escatológica, o Rolo se revela um documento de definição de comportamento religioso. Ele quer levar uma comunidade privada de poder militar e longe do campo de batalha

${ }^{15}$ Segundo Collins, estas implicações sectárias aparecem implícitas no Rolo da Guerra. Sua relação com o Israel nacional ainda é ambígua, possivelmente indicando um estágio pré-sectário da comunidade. Mas a mistura do dualismo "luz e trevas" com a tradição da guerra santa tinha o potencial de produzir o sectarismo presente em outros documentos de Qumran, como é o caso do Manual de Disciplina (Cols III-V). Cf. COLLINS, John J. The Mythology of Holy War in Daniel and the Qumran War Scroll, p. 610.

${ }^{16}$ Segundo Collins, o conhecimento de 1QM de táticas militares era possivelmente derivado da experiência dos hasmoneus, do exército herodiano e da observação de exércitos estrangeiros, como o exército romano. Cf. COLLINS, John J. Apocalypticism in the Dead Sea Scrolls, p. 96.

${ }^{17}$ Para Bauckham, os sacerdotes e levitas oram antes, durante e depois da guerra, e tocam as trombetas tanto para dirigir as tropas quanto para chamar a atenção divina para o combate. Sem eles, a guerra não poderia ser uma guerra santa. Cf. BAUCKHAM, Richard. The Climax of prophecy, p. 222. 
a se preparar para, no fim dos tempos, participar do conflito final contra seus adversários. Ainda mais: ele, se colocado em prática, os habilitaria a receber o apoio das hostes celestiais nesta que seria a última guerra da humanidade. Isso conduz a comunidade a viver já em função do conflito, com tudo o que isso poderia implicar. Afinal, para guerrear ao lado dos anjos era preciso o preparo cotidiano de toda a comunidade. Quem fracassasse poderia ficar de fora do conflito final.

Não há no texto nenhuma indicação de quando a guerra iria começar, o que levava toda a comunidade a viver em estado de alerta. Isso a transforma numa comunidade escatológica, a comunidade do fim dos tempos.

O Rolo da Guerra, então, apesar de apresentar um conflito para os dias futuros, funciona como um espelho dos dias presentes. É bem possível que sua comunidade tenha incorporado no seu dia a dia as práticas descritas nele, porque este era o caminho para participar do resultado esperado, a vitória final ao lado de Deus e seus anjos, contribuindo para produzir um forte senso de identidade entre seus leitores ${ }^{18}$.

\section{O Apocalipse de João}

O Apocalipse de João é o último livro do cânon cristão. Ele foi escrito por um judeu palestino que interpretava seus próprios dias como os dias da intervenção final de Deus. Os estudiosos costumam datá-lo para o final do primeiro século, um pouco menos de três décadas após a destruição de Jerusalém pelos soldados romanos em 70 d.C. ${ }^{19}$.

\footnotetext{
${ }^{18}$ DUHAIME, Jean. The War Texts, p. 61.

${ }^{19}$ KÜMMEL, Werner Georg. Introdução ao Novo Testamento. São Paulo: Paulinas, 1982, pp. 613-617; VINSON, Richard B. The Social World of the Book of Revelation. In: Review \& Expositor, 98, 2001, p. 11; ADRIANO FILHO, José. O Apocalipse de João como relato de uma experiência visionária: Anotações em torno da estrutura do livro. In: RIBLA, 34, p. 7; MCDOWELL, E. A. A soberania de Deus na história: a mensagem e significado de Apocalipse. Rio de Janeiro: JUERP, 1980, p. 17.
} 
Percebendo-se perseguido pela sociedade romana, ele se refugia na Ilha de Patmos e escreve para sete igrejas que estão na Ásia Menor. Aparentemente, no seu livro ele registrou as experiências visionárias e revelações que teria recebido nesta pequena ilha perto da costa do Mediterrâneo.

Sua obra pode ser dividida em três partes ${ }^{20}$. Na primeira, ele escreve especificamente para as sete igrejas. Na segunda seção do livro, João descreve sua participação numa espécie de culto no céu. Neste culto, o visionário é apresentado aos principais personagens do livro, que o acompanharão até o final: o Ancião sentado sobre o trono, os Quatro Viventes, os Vinte e Quatro Anciãos e vários seres angelicais. O principal personagem é o Cordeiro. É ele que, durante uma parte do culto, recebe um rolo selado com sete selos, que serão quebrados para revelar para João a natureza de eventos que se deram ou se darão sobre a comunidade de "santos"21. A cada selo corresponde uma revelação, até o sétimo que, em vez de encerrar a série, se desdobra em outro grupo de sete elementos, desta vez sete trombetas. Como os selos, cada trombeta está relacionada com um evento, numa escala crescente de intensidade, que culmina com a audição de um hino que comemora o reinado do Cordeiro e a abertura do santuário celestial.

${ }^{20}$ Conferir as principais propostas de estruturação do Apocalipse em COLLINS, Adela Yarbro. The Combath Myth in the Book of Revelation. Eugene: Wipf and Stock Publishers, 2001, pp. 13-44.

${ }^{21}$ Evitaremos, neste artigo, recorrer aos termos "cristãos" e "cristãs" para descrever João, seu texto e sua audiência. O visionário não usou estes termos, o que poderia indicar que ele não os conhecia, ou não gostava deles. Friesen parece acertar ao sinalizar que não existe evidência do uso destes termos pelas igrejas antes do segundo século. Eles ocorrem apenas três vezes no Novo Testamento, geralmente em contextos ambíguos ou como rótulo por pessoas hostis de fora das comunidades (At 11.26; 26.28; 1Pe 4.16). Cf. FRIESEN, Steve. Sarcasm in Revelation 2-3: Churches, Christians, True Jews, and Satanic Synagogues. In: BARR, David L. (ed.) The Reality of Apocalypse: Rhetoric and Politics in the Book of Revelation. Atlanta: Society of Biblical Literature, 2006, p. 142; também DUFF, Paul B. "The Synagogue of Satan": Crisis Mongering and the Apocalypse of John. In: BARR, David L. (ed.) The Reality of Apocalypse: Rhetoric and Politics in the Book of Revelation. Atlanta: Society of Biclical Literature, 2006, p. 148. No lugar destas expressões, recorreremos ao termo "santo", mais apropriado para designar os seguidores de Jesus no período histórico em questão. 
A terceira parte do livro não se concentra mais no culto, mas numa guerra. O conflito começa quando o Dragão falha tanto em destruir a criança messiânica quanto num confronto com Miguel e seus anjos no céu. Derrotado, foi expulso para a terra. Sua reação é instaurar uma guerra contra os demais filhos da mãe da criança messiânica, "os que guardam os mandamentos de Deus e apresentam o testemunho de Jesus" (Ap 12.17). Sua estratégia bélica consiste em levantar duas bestas, uma do mar e outra da terra. São elas que implementam o conflito. Os lados do confronto são logo definidos, já que as bestas marcam seus aliados com um número na testa e na mão. Em contrapartida, os aliados do Cordeiro recebem seu selo, o que define também o início da reação na guerra contra o Dragão, as bestas e seus aliados. Sobre o monte Sião, 144.000 homens virgens se reúnem em volta do Cordeiro, prontos para seguir com ele aonde ele for. Do confronto inicial, entretanto, resulta a morte desses guerreiros, cujo sangue é derramado em grande quantidade, descrito como uma ceifa escatológica. Mas suas mortes não representam suas derrotas, já que eles aparecem logo depois como os vencedores sobre um mar de vidro cantando o cântico de Moisés e do Cordeiro. Estas mortes completam o sangue que precisa ser derramado, provocando a ira de Deus sobre a humanidade, na forma de sete taças. Cada taça é derramada sobre elementos da terra, até que a última atinge a própria Babilônia, acusada de derramar o sangue dos profetas, dos "santos" e de todos que morreram. Após o juízo sobre a grande cidade, finalmente, o Guerreiro Celestial desce do céu com suas hostes para enfrentar a coalizão adversária. Sua vitória se dá em duas fases. Na primeira, as bestas são lançadas num lago de fogo, todo seu exército é morto com a espada que sai da sua boca e o Dragão é preso por mil anos. A segunda fase da guerra só se levanta após o término deste período intermediário de paz, quando o Dragão, novamente solto, mobiliza outro exército contra os "santos". O fim desta coalizão, entretanto, é uma nova derrota, desta vez definitiva, quando o Dragão é jogado no mesmo lago de fogo onde já estavam as duas bestas. Seu exército também é queimado com fogo que cai do céu. Com o fim da guerra escatológica, o visionário finalmente descreve as bodas do Cordeiro, a descida da Nova Jerusalém, o lar final dos "santos" de Deus. 
Por este resumo, percebemos que a guerra ocupa um espaço impressionante no livro de João. O próprio substantivo пó $\lambda \in \mu \circ \varsigma$ (guerra) aparece no Apocalipse mais do que em qualquer outra obra do Novo Testamento. Das 18 ocorrências do termo, nove estão no Apocalipse (três delas na segunda seção, e as outras seis na terceira) ${ }^{22}$.

Das sete ocorrências do verbo $\pi 0 \lambda \in \mu \mu^{\prime} \omega$ (guerrear), raro no Novo Testamento, seis estão no Apocalipse ${ }^{23}$, concentradas especificamente na terceira seção. Apenas uma ocorrência aparece fora deste bloco, na seção de cartas.

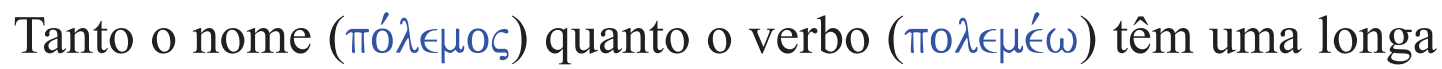
história textual, já aparecendo nos textos de Homero e Hesíodo como

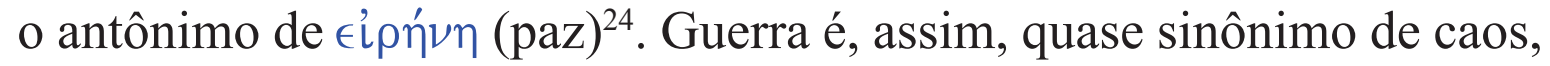
fenômeno esse que a esperança apocalíptica esperava terminar com a intervenção divina. Desta forma, apesar de guerra ser um assunto comum aos autores antigos, havia a esperança de que no fim um conflito escatológico pusesse termo a todos as guerras.

No Apocalipse, a guerra é dirigida contra as duas testemunhas proféticas (11.7), contra a comunidade de "santos" (12.17 e 13.17) e contra o Cordeiro (17.14). Por sua vez, o guerreiro escatológico faz guerra contra os impenitentes da igreja de Tiatira (2.16), contra as bestas (19.19) e contra o Dragão (20.8).

$\mathrm{O}$ verbo $\nu \iota \kappa \alpha ́ \omega$ (vencer) também tem grande importância no vocabulário de Apocalipse. Das 28 ocorrências no Novo Testamento, 17 estão em Apocalipse. Destas, sete estão concentradas na primeira seção, outras três na segunda e o restante (cinco ocorrências) na terceira ${ }^{25}$.

${ }^{22}$ Mt 24.6; Mc 13.7; Lc 14.31; Lc 21.9; 1 Co 14.8; Hb 11.34; Tg 4.1; Ap 9.7, 9; 11.7; $12.7,17 ; 13.7 ; 16.14 ; 19.19 ; 20.8$.

${ }^{23} \mathrm{Tg} 4.2 ;$ Ap $2.16 ; 12.7 ; 13.4 ; 17.14 ; 19.11$.

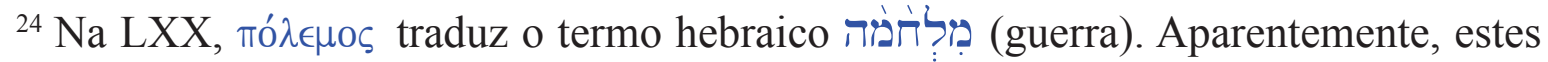
termos estavam relacionados com os negócios divinos. Os deuses Ares e Pales Atenas eram os deuses da guerra, e estavam frequentemente por trás das guerras dos mortais. Cf. BAUERNFEIND, Otto. Пó $\lambda \epsilon \mu \circ$, , то $\lambda \in \mu^{\prime} \in \omega$. In: KITTEL, Gehard (ed.) Theological Dictionary of the New Testament. Vol. VI, pp. 503-504.

${ }^{25}$ Lc 11.22; Jo 16.33; Rm 3.4; Rm 12.21; 1Jo 2.13; 1Jo 4.4; 1Jo 5.4; Ap 2.7, 11, 17 , $26 ; 3.5,12,21 ; 5.5 ; 6.2 ; 11.7 ; 12.11 ; 13.7 ; 15.2 ; 17.14 ; 21.7$. 
Este verbo, na primeira seção, parece constituir um convite para que a audiência se envolva em algum tipo de conflito, apesar da natureza do conflito só ser esclarecida nas seções seguintes, especificamente na terceira seção.

O termo $\sigma \tau \rho \alpha ́ \tau \epsilon \cup \mu \alpha$ (exército) aparece oito vezes no Novo Testamento. Destas, a metade das aparições está no Apocalipse de João ${ }^{26}$. João vê em Apocalipse 9.15 um exército demoníaco pronto para destruir um terço dos povos da terra. Em outra visão, Apocalipse 19.14, ele vê o exército celestial do guerreiro celestial, o verbo de Deus, o Rei dos Reis e Senhor dos Senhores pronto para enfrentar a coalizão das bestas (Ap 19.19).

Baumgarten argumenta que o visionário não vê uma contraparte positiva para enfrentar o exército demoníaco da terra, ou seja, outro exército da terra, composto de fiéis que, impulsionado pela fé, se aliariam ao exército celestial e ajudariam o Guerreiro Celestial. Segundo este autor, os "santos" entendiam que esse rei não precisaria de ajuda, nem mesmo a desejaria ${ }^{27}$. Entretanto, é justamente esse exército positivo que parece se levantar em Apocalipse 14.1. Os guerreiros do Cordeiro estão reunidos para enfrentar o exército das bestas. A estrutura dos exércitos parece ser esta: O Dragão versus o Guerreiro Celestial; as bestas versus o Cordeiro; o exercito das bestas versus o exército do Cordeiro. A forma como este exército positivo da terra participa do conflito, entretanto, está intimamente relacionada com o testemunho e com o martírio.

Quanto aos instrumentos de guerra, $\rho \circ \mu \phi \alpha i \alpha$ (espada), aparece sete vezes no Novo Testamento. Destas, seis estão no livro do Apocalipse ${ }^{28}$. Destas ocorrências, apenas Apocalipse 6.8 parece usar o termo no sentido literal; as demais surgem de forma figurada, onde $\rho$ o $\mu \phi \alpha i ́ \alpha$ é a pala-

${ }^{26}$ Mt 22.7; Lc 23.11; At 23.10, 27; Ap 9.16; 19.14, 19.

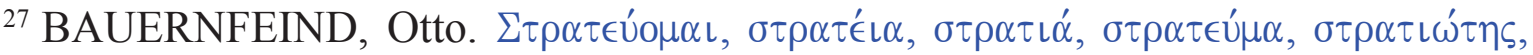

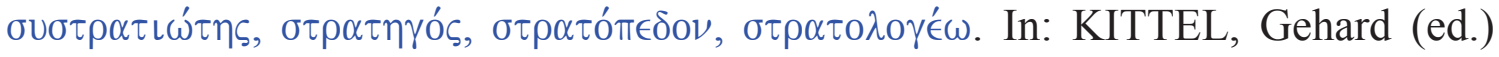
Theological Dictionary of the New Testament. Vol. VII. Grand Rapids: Eerdmans, 1968, p. 708.

${ }^{28}$ Lc 2.35; Ap 1.16; 2.12, 16; 6.8; 19.15, 21. 
vra do Jesus Glorificado ${ }^{29}$. De qualquer forma, sobressai a importância deste instrumento de guerra para a narrativa do visionário João, quando comparado com os demais textos do Novo Testamento.

Outro termo grego também traduzido como "espada", $\mu \alpha \dot{\alpha} \chi\llcorner\llcorner\rho \alpha$, entretanto, tem pouco uso no Apocalipse. Das 29 ocorrências no Novo Testamento, apenas quatro estão no livro de João. Seu uso mais freqüente é mesmo nos Evangelhos Sinóticos (15 ocorrências) ${ }^{30}$. O sentido mais imediato de $\mu \alpha \dot{\alpha} \alpha\llcorner\rho \alpha$ é faca, sendo um instrumento utilizado em sacrifício, cozinha, tosquia e nas ocupações de curtidor e jardineiro. Como arma, indicava uma pequena espada de defesa, diferenciada então de $\rho$ o $\mu \phi \alpha i \alpha$, normalmente uma espada

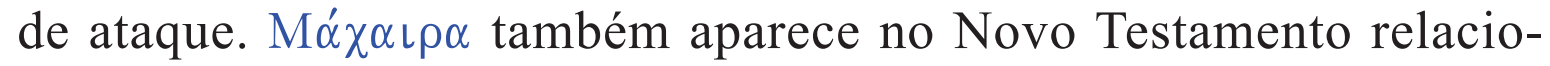
nada com a "palavra", em Hebreus 4.12, cuja idéia, entretanto, não guarda relação com punição ou destruição, mas com a revelação dos pensamentos ou percepções do coração, quase como um bisturi ou um instrumento cirúrgico ${ }^{31}$.

A predominância de $\rho \circ \mu \phi \alpha \iota \alpha$, quando comparada com $\mu \alpha \alpha \chi \alpha \iota \rho \alpha$, em Apocalipse pode estar relacionada com a natureza violenta do conflito. A guerra nesta obra tem como função punir as hostes adversárias dos "santos" de Deus. Isso poderia indicar a razão do uso de $\rho \circ \mu \phi \alpha \iota \alpha$ em detrimento de $\mu \alpha ́ \alpha \alpha\llcorner\rho \alpha$.

Por sua vez, um instrumento que não é essencialmente forjado para uso bélico, mas que parece assumir essa função no Apocalipse é a $\delta \rho \in ́ \pi \alpha \nu 0 \nu$ (foice). Das oito ocorrências do termo no Novo Testamento, sete estão no Apocalipse (a outra ocorrência é Mc 4.29). Todas as ocorrências deste termo estão concentradas no capítulo 14 .

A ceifa foi definida pelo autor do Evangelho de Mateus de uma forma bem específica: "O inimigo que o semeou é o diabo; a ceifa é a consumação do século, e os ceifeiros são os anjos” (Mt 13.39). Outra passagem

\footnotetext{
${ }^{29}$ MICHAELIS, Wilhelm. $\rho \circ \phi \alpha \iota \alpha$. In: KITTEL, Gehard (ed.) Theological Dictionary of the New Testament. Vol. VI. Grand Rapids: Eerdmans, 1968, pp. 993-998.

${ }^{30}$ Mt 10.34; 26.47, 51, 55; Mc 14.43, 47; Lc 21.24; 22.36, 38, 49, 52; Jo 18.10; At 12.2; 16.27; Rm 8.35; 13.4; Ef 6.17; Hb 4.12; 11.34, 37; Ap 6.4; 13.10, 14.

${ }^{31}$ MICHAELIS, Wilhelm. M $\alpha \chi \alpha \iota\llcorner\alpha$. In: KITTEL, Gehard (ed.) Theological Dictionary of the New Testament. Vol. IV. Grand Rapids: Eerdmans, 1968, pp. 524-527.
} 
usa a ceifa e a foice como imagens do tempo final: "Não dizeis vós que ainda há quatro meses até à ceifa? Eu, porém, vos digo: erguei os olhos e vede os campos, pois já branquejam para a ceifa" (Jo 4.35).

Para a ceifa como uma imagem positiva, conferir, parcialmente, Pringent ${ }^{32}$. Segundo ele, a ceifa seria uma referência ao julgamento dos fiéis, enquanto a vindima simbolizaria o juízo sobre Babilônia ${ }^{33}$. Barr, entretanto, entende ambas as imagens como referências positivas. $\mathrm{O}$ sangue que cobriria a terra, neste caso, seria o sangue do Cordeiro ${ }^{34}$. É possível entender, assim, que a imagem não apenas descreva o sangue de Jesus, mas também dos seus 144.000 seguidores $^{35}$.

A hora da ceifa é o momento de colher as uvas, imagem que representaria, em Apocalipse 14, a morte dos guerreiros do Cordeiro que foram reunidos sobre o Monte Sião. Estas mortes, entretanto, funcionam como sacrifício agradável a Deus. Quando o lagar da ira de Deus estiver cheio com o sangue desses mártires, seu juízo será derramado sobre os adversários, como parece indicar Apocalipse 6.11: "Então, a cada um deles foi dada uma vestidura branca, e lhes disseram que repousassem ainda por pouco tempo, até que também se completasse o número dos seus conservos e seus irmãos que iam ser mortos como igualmente eles foram", e 15.1: "Vi no céu outro sinal grande e admirável: sete anjos tendo os sete últimos flagelos, pois com estes se consumou a cólera de Deus."

Isso poderia indicar que a foice é realmente uma arma contra as bestas, mas funcionaria de forma indireta, ao colher o sangue dos "santos" do Cordeiro. Simbolizaria a morte dos "santos", o que, no final, é a arma de vitória desses guerreiros.

Thompson apontou que, na perspectiva do Apocalipse, vitória e reinado estão diretamente ligados a sofrimento e crucificação ${ }^{36}$. A vitó-

\footnotetext{
${ }^{32}$ PRIGENT, Pierre. O Apocalipse, p. 274.

${ }^{33}$ De forma similar, FIORENZA, Elisabeth Schüssler. Revelation, pp. 90-91.

${ }^{34}$ BARR, David L. Tales of the End, p. 130.

${ }^{35}$ Neste mesmo sentido, conferir CAIRD, G. B. A Commentary on the Revelation of St. John the Divine, pp. 189-195.

${ }^{36}$ THOMPSON, Leonard. "A Sociological Analysis of Tribulation in the Apocalypse of John”. In: Semeia, 36, 1986, p. 151.
} 
ria através do sangue derramado se manifesta através das imagens combinadas de leão e ovelha (Ap 5.5-6), cordeiro ensangüentado e palavra de Deus vestida em sangue (Ap 19.13).

Assim, a vida para os "santos" virá pela morte, exatamente como foi com Jesus. Neste sentido, João conecta tribulação e opressão com outros temas paralelos, como desejo de vingança, retribuição, vinda do juízo sobre todos os que se opõe à Cristo e aos "santos". O martírio, neste caso, é a imitação do rei crucificado ${ }^{37}$.

Deve-se destacar, ainda, algumas ausências curiosas. Apesar de

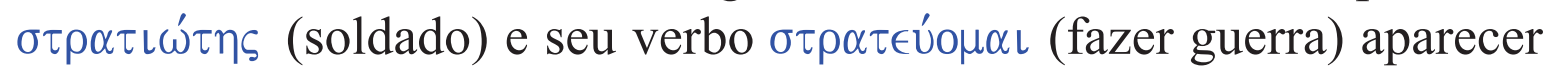
várias vezes no Novo Testamento, ele está ausente do Apocalipse. Isso poderia estar relacionado com o aspecto voluntário da guerra no livro do visionário. João não espera o envolvimento de qualquer soldado profissional, mas a adesão voluntária de fiéis que deixam suas atividades cotidianas para se envolver no conflito (como no período em que a guerra santa se manifestava como fenômeno histórico). Neste sentido, não é um soldado profissional que faz a guerra. Esta, por sua vez, não é desenvolvida com técnicas militares especializadas, mas com o recurso de práticas religiosas, como o testemunho, o culto e a oração dos "santos" (como no Rolo da Guerra de Qumran).

Apesar do foco da primeira seção do Apocalipse residir nas cartas (Ap 1-3) e da segunda seção no culto celestial (Ap 4-11), a tradição do confronto está presente em todo o livro. A guerra, que será descrita detalhadamente na terceira seção (Ap 12-22), surge mencionada e antecipada nas duas seções anteriores.

Esta terceira seção é o que poderia ser apropriadamente chamada de uma narrativa de guerra santa escatológica, nos moldes do Rolo da Guerra de Qumran. A seqüência temporal não é linear ${ }^{38}$. Mesmo assim, ainda existe um sentido de movimento para frente. A história começa com a Mulher e o Dragão e termina com as bodas do Cordeiro. O pri-

${ }^{37}$ THOMPSON, Leonard. "A Sociological Analysis of Tribulation in the Apocalypse of John", p. 153.

${ }^{38}$ A síntese da seção da guerra escatológica depende de BARR, David L. Tales of the End, pp. 102-148. 
meiro estágio da guerra está descrito em Apocalipse 12.1-1839. Uma guerra irrompe no céu, resultando na expulsão do Dragão para a terra. $\mathrm{O}$ Dragão tenta destruir a criança messiânica, mas falha no momento em que ela é arrebatada para o céu. Diante disto, o Dragão tenta destruir a Mulher, que é protegida no deserto. Depois de fracassar na perseguição da Mulher, o dragão se dirige para sua descendência, os outros filhos da Mulher. Estes filhos são aqueles que guardam os mandamentos de Deus e sustentam o testemunho de Jesus. Tal descrição claramente descreve a audiência do Apocalipse. Este estágio da guerra está no passado da comunidade de João, e teria como função justificar para esta audiência uma eminente perseguição ${ }^{40}$.

O segundo estágio da guerra se dá no levantamento dos aliados do Dragão. Ele convoca duas bestas, que desenvolvem a guerra instaurada pelo Dragão. Como o dragão, estas bestas derivam de antigas histórias de conflito. Conhecidas na tradição hebraica como Leviatã ou Behemoth, elas representam forças antigas do caos que Deus venceu para trazer ordem ao mundo. São personagens derivados de antigas histórias cananitas e babilônicas de criação e conflito. Elas foram usadas pelos antigos autores para expressar a vitória de Deus sobre o caos, tanto no início da criação, na história de Israel e no final dos tempos. A diferença é que o conflito histórico agora é contra o Império Romano e sua estrutura religiosa ${ }^{41}$. Estes dois agentes agem de forma distinta, mas complementar, à forma como o Dragão perseguiu a Mulher. O primeiro age pela força; o segundo pela decepção, sedução e coerção.

${ }^{39}$ CHEVITARESE, André Leonardo. Dragão, serpente e mulher. As bases helenísticas do capítulo 12 do Apocalipse de João, o visionário: "O capítulo 12 é chave para se entender toda a narrativa do Apocalipse"; também para Kovacs e Rowland, para quem o capítulo 12 é uma abrupta transição dentro do livro, a introduzir um complexo inteiro de visões. Cf. KOVACS, Judith; ROWLAND, Christopher C. Revelation, p. 134.

${ }^{40}$ HENTEN, Jan Willem. Dragon Myth and Imperial Ideology in Revelation 1213, p. 202.

${ }^{41}$ HENTEN, Jan Willem. Dragon Myth and Imperial Ideology in Revelation 1213, p. 201; COLLINS, Adela Yarbro. The Combath Myth in the Book of Revelation, p. 232. 
O terceiro estágio da guerra pode ser denominado de "resposta do Cordeiro". Ele começa sua reação com a reunião de um exército de oposição sobre o monte Sião. São os 144.000 selados de todas as tribos de Israel (eles já apareceram em Apocalipse 7.1-8). A atenção retorna para o céu, de onde surge o Filho do homem. Esta figura introduz a cena da colheita, uma cena de guerra com imagens muito fortes. A figura celestial é Jesus. O campeão aparece. A vitória está garantida. Mas a situação não se desenrola como se esperaria. Os guerreiros do Cordeiro não vencem pela força, mas pelo martírio. Após suas mortes, eles aparecem já na forma dos vencedores da besta que cantam o Cântico de Moisés e do Cordeiro. Como resultado dessas mortes, completou-se o lagar da ira de Deus, que será derramado sobre a terra na forma das sete taças com as sete pragas finais sobre a terra. O templo é aberto e de lá vêm os anjos com as taças escatológicas. A seqüência evoca as sete trombetas, mas a ação é mais definitiva. Eles bombardeiam a terra sucessivamente com suas taças, destruindo aspectos diferentes da dominação do mal sobre a terra.

O clímax das taças de julgamento está na descrição da queda de Babilônia. A derrota do Dragão é descrita através da divisão do inimigo. Um a um eles vão caindo, começando com a grande Prostituta. A cena inteira está ligada com a série de taças, que é concluída com uma liturgia celestial nos moldes do culto diante do Trono de Apocalipse 4-5.

Finalmente, chega a fase final da guerra. O Guerreiro Celestial aparece do céu em todo o seu esplendor militar e alcança fácil vitória sobre as bestas. Ele surge em um cavalo branco, com seu nome enaltecido, comandando um exército celestial, pronto para a guerra. Esta é a figura na qual culminam as demais figuras de guerra. Ele julga e guerreia. Mas ainda não chegou o fim. Um período interino de paz foi estabelecido. Um anjo descerá do céu e prenderá o dragão. Se o dragão foi expulso para a terra por Miguel, agora ele é novamente expulso, desta vez para o abismo. Somente após o milênio Satã é libertado, reúne um novo exército, marcha outra vez contra o acampamento dos "santos". Entretanto, cai fogo do céu e derrota todo o exército adversário. Mais uma vez a batalha é vencida sem conflito, e agora Satanás é jogado no lago de fogo. A partir de então o visionário se dedica a narrar a cena da nova criação. 


\section{A guerra santa no Rolo da Guerra de Qumran e no Apocalipse de João}

Como Von Rad mesmo já havia sinalizado, não é necessário ter a presença de todos os elementos da tipologia presentes para se caracterizar uma narrativa de guerra santa ${ }^{42}$. Por isso, mesmo tendo alguns elementos da tipologia ausentes da narrativa da guerra de Apocalipse, aparentemente confirmamos que o modelo básico da história de guerra que João narra é a tradição da guerra santa ${ }^{43}$.

Duas décadas depois da guerra judaico-romana, o visionário João volta a usar esta tradição num contexto histórico muito semelhante ao subjacente ao Rolo da Guerra de Qumran. A história de guerra de João também quer orientar um grupo de fiéis a se portar diante de um conflito, desta vez contra as bestas do Dragão. A narrativa evoca a tradição da guerra santa escatológica contra as nações; mas evoca também o espaço do culto e dos rituais religiosos (Ap 14.2; comparar com 2 Cr 20.28 e 1QM 4.4-5). No primeiro cenário, os "santos" que acompanham o Cordeiro se portam como guerreiros e estão prontos para guerrear; no segundo cenário, eles estão no céu, envolvidos com hinos e canções celestiais que somente eles podem aprender.

No momento em que descreve o ajuntamento do exército do Cordeiro, João os descreve desta forma: "São estes os que não se macularam com mulheres, porque são castos. São eles os seguidores do Cordeiro por onde quer que vá. São os que foram redimidos dentre os homens, primícias para Deus e para o Cordeiro; e não se achou mentira na sua boca; não têm mácula." (Ap 14.4-5).

Como eles formam um exército lutando a guerra do Cordeiro, como no Rolo da Guerra, eles devem permanecer, durante o combate, ritualmente puros. Num contexto de conflito iminente, em que os discípulos passam a se ver numa contínua situação de guerra, a abstinência sexual se transforma numa demanda por virgindade ou celibato contínuo. A necessidade do preparo constante para o confronto escatológico teria

\footnotetext{
${ }^{42}$ VON RAD, Gerhard. Holy War in Ancient Israel, p. 51.

${ }^{43}$ BAUCKHAM, Richard. The Climax of Prophecy, p. 212.
} 
o potencial de gerar um ideal de virgindade. Para participar da vitória do Cordeiro, era necessário estar preparado para se envolver no conflito quando ele se manifestasse, e isto envolvia o celibato.

Se no Rolo da Guerra, os sacerdotes e levitas têm um papel fundamental no conflito, o Apocalipse, entretanto, vai mais longe. Seus guerreiros são todos, igualmente, sacerdotes de Deus e do Cordeiro. E não apenas dirigirão o conflito, como em 1QM, mas se envolverão nele diretamente. $\mathrm{O}$ visionário idealiza, assim, uma comunidade de guerreiros-sacerdotes do Cordeiro que está em estado de espera da guerra final. Dentro deste imaginário, guerra e culto se confundem, pois os guerreiros lutam como se fossem sacerdotes de Deus.

Tanto no Apocalipse, quanto no Rolo da Guerra, a guerra santa é evento escatológico, a se dar no fim dos tempos, e teria o envolvimento não apenas dos anjos, mas dos "santos" no meio deles. Ambos divergem, entretanto, na forma como se dará essa participação. O Rolo da Guerra imagina um envolvimento direto dos guerreiros no conflito; o Apocalipse visualiza a participação na forma do testemunho e do martírio ${ }^{44}$.

De forma semelhante ao que aconteceu no Rolo da Guerra, essa tradição, quando lançada sobre o grupo de guerreiros-sacerdotes, tem o potencial de produzir na audiência do Apocalipse um forte comportamento ascético, onde as barreiras que a separam do mundo são fortificadas e levantadas. Ascetismo e martírio aparecem como elementos predominantes, tanto para vencer as bestas, quanto para participar do culto a Deus.

Há um dualismo sectário e radical tanto no Rolo da Guerra quanto no Apocalipse. Ambos os textos se apresentam mergulhados na tradição da guerra santa, com a missão de definir limites e fronteiras de suas respectivas comunidades. Os autores ou redatores destes documentos prescrevem a identidade de sua audiência, projetando-a na descrição de um grupo de guerreiros do final dos tempos.

\footnotetext{
${ }^{44}$ Reddish analisou o tema no Apocalipse e levantou a hipótese de que o livro foi escrito para falar do martírio e sobre o martírio. Cf. REDDISH, Mitchell G. "Martyr Christology in the Apocalypse". In: Journal for the Study of the New Testament, 33,1988, p. 86. Jesus, neste caso, é o proto-mártir que os seus seguidores devem imitar.
} 


\section{Referências Bibliográficas}

ADRIANO FILHO, José. O Apocalipse de João como relato de uma experiência visionária: Anotações em torno da estrutura do livro. In: Revista de Interpretação Bíblica Latino-Americana, 34, 1999, pp. 7-29.

BARR, David L. Tales of the End: a Narrative Commentary on the Book of Revelation. Santa Rosa: Polebridge Press, 1998.

BAUCKHAM, Richard. The clímax of Prophecy. London: T \& T Clark, 1993.

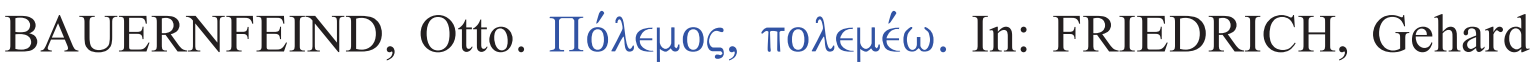
(ed.). Theological Dictionary of the New Testament. Vol. VI. Grand Rapids: Eerdmans, 1968, pp. 502-515.

BAUERNFEIND, Otto. $\Sigma \tau \rho \alpha \tau \in \dot{O} 0 \mu \alpha \iota, \sigma \tau \rho \alpha \tau \tau^{\prime}\llcorner\alpha, \sigma \tau \rho \alpha \tau \iota \alpha, \kappa \tau \lambda$. In: KITTEL, Gehard (ed.) Theological Dictionary of the New Testament. Vol. VII. Grand Rapids: Eerdmans, 1968, pp. 701-713.

CAIRD, G. B. A Commentary on the Revelation of St. John the Divine. New York: Harper \& Row Publishers, 1966.

CHEVITARESE, André Leonardo. Dragão, serpente e mulher. As bases helenísticas do capítulo 12 do Apocalipse de João, o visionário. In: Estudos de Religião, 22, 2002, pp. 11-36.

COLLINS, Adela Yarbro. The Combath Myth in the Book of

Revelation. Eugene: Wipf and Stock Publishers, 2001.

COLLINS, J. J. Dualism and Eschatology in 1QM: a Reply to P. R.

Davies. In: Vetus Testamentum, 29/2, 1979, pp. 212-215.

COLLINS, John J. Apocalypticism in the Dead Sea Scrolls. New York: Routledge, 1997.

DUFF, Paul B. "The synagogue of Satan": Crisis Mongering and the Apocalypse of John. In: BARR, David L. (ed.). The Reality of Apocalypse: Rhetoric and Politics in the Book of Revelation. Atlanta: Society of Biblical Literature, 2006, pp. 147-168.

DUHAIME, Jean. The War Texts: 1QM and Related Manuscripts. New York: T\&T Clark International, 2004.

FIORENZA, Elisabeth Schüssler. Revelation: Vision of a Just World. Minneapolis: Augsburg Fortress, 1991. 
FRIESEN, Steve J. Sarcasm in Revelation 2-3: Churches, Christians, True Jews, and Satanic Synagogues. In: BARR, David L. (ed.). The Reality of Apocalypse: Rhetoric and Politics in the Book of Revelation. Atlanta: Society of Biblical Literature, 2006, pp. 127-144.

GARCÍA MARTÍNEZ, Florentino. Textos de Qumran. Petrópolis: Vozes, 1995.

GARCIA MARTINEZ, Florentino. The Dead Sea Scrolls Study Edition (2 vols). Leiden: Brill, 2000.

GARD, Daniel L. YHWH as God of War and God of Peace. Fort Wayne: Concórdia Theological Seminary, 2004.

HENTEN, Jan Willem. Dragon Myth and Imperial Ideology in Revelation 12-13. In: BARR, David L. The Reality of Apocalypse: Rethoric and politics in the Book of Revelation. Atlanta: Society of Biblical Literature, 2006, pp. 181-203.

KOVACS, Judith; ROWLAND, Christopher C. Revelation. Oxford: Blackwell Publishing, 2004.

KUMMEL, W. G. Introdução ao Novo Testamento. Trad. Isabel L.

Ferreira e J. P. Neto. São Paulo: Paulinas, 1982.

MCDOWELL, E. A. A soberania de Deus na história: a mensagem e significado de Apocalipse. 3. ed. Trad. Robert G. Bratcher e W. Kaschel. Rio de Janeiro: JUERP, 1980.

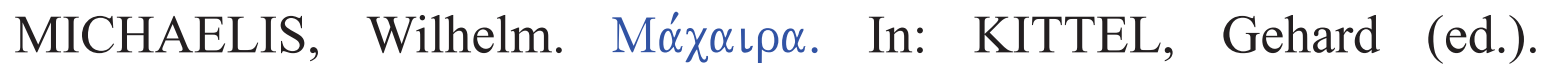
Theological Dictionary of the New Testament. Vol. IV. Grand Rapids: Eerdmans, 1968, pp. 524-527.

MICHAELIS, Wilhelm. $\rho \circ \phi \alpha \iota \alpha$. In: KITTEL, Gehard (ed.). Theological Dictionary of the New Testament. Vol. VII. Grand Rapids: Eerdmans, 1968, pp. 993-998.

OLLENBURGER, Ben C. Introduction: Gerhard von Rad's Theory of Holy War. In: VON RAD, Gerhard. Holy War in Ancient Israel. Grand Rapids: Eerdmans Publishing Co., 1991, pp. 1-33.

PAGELS, Elaine. As origens de satanás: um estudo sobre o poder que as forças irracionais exercem na sociedade moderna. Trad. Ruy Jungmann. Rio de Janeiro: Ediouro, 1996.

PARKER, James O. The genres of the Dead Sea War Scroll. 1997. Tese. (Doutorado em Filosofia) - Kansas City, Mid-America Baptist Theological Seminary. 1997. 
PRIGENT, Pierre. O Apocalipse. Trad. Luiz João Baraúna. São Paulo: Loyola, 1993.

REDDISH, Mitchell G. Martyr Christology in the Apocalypse. In: Journal for the Study of the New Testament, 33, 1988, pp. 85-95. THELML, Neyde; BUSTAMANTE; Regina Maria da Cunha. História comparada: olhares plurais. In: Revista de História Comparada, 1/1, 2007, pp. 1-23.

THIERING, Barbara. The Biblical Source of Qumran Asceticism. In: Journal of Biblical Literature, 93/3, 1974, pp. 429-444.

THOMPSON, Leonard L. A Sociological Analysis of Tribulation in the Apocalypse of John. In: Semeia, 36, 1986, pp. 147-174.

TROMPF, Garru W. Introduction I: The Long History of Dead Sea Scrolls Scholarship. In: The Journal of Religious History, 26/2, 2002, pp. 123-144.

VEYNE, Paul. O inventário das diferenças. $1^{\mathrm{a}}$ ed. Trad. José Vasco Marques. Lisboa: Gradiva, 1989.

VINSON, Richard B. The Social World of the Book of Revelation. In: Review \& Expositor, 98/1, 2001, pp. 11-33.

VON RAD, Gerhard. Holy War in Ancient Israel. Grand Rapids: Eerdmans Publishing Co., 1991.

WINSON, Edmund. Os manuscritos do Mar Morto. São Paulo: Companhia das Letras, 1994. 